Open Access

\title{
An indeterminate mucin-producing cystic neoplasm containing an undifferentiated carcinoma with osteoclast-like giant cells: a case report of a rare association of pancreatic tumors
}

Marco Chiarelli', Angelo Guttadauro², Martino Gerosa', Alessandro Marando ${ }^{3}$, Francesco Gabrielli², Matilde De Simone ${ }^{4}$ and Ugo Cioffi ${ }^{*}$

\begin{abstract}
Background: Only few case reports of mucinous cystic pancreatic neoplasm containing an undifferentiated carcinoma with osteoclast-like giant cells have been described in the literature. In the majority of cases this unusual association of tumors seems related to a favorable outcome. We present the second case of an indeterminate mucin-producting cystic neoplasm containing an area of carcinoma with osteoclast-like giant cells. The specific features of the two histotypes and the rapid course of the disease make our clinical case remarkable.
\end{abstract}

Case presentation: A 68 year old female came to our attention for a pancreatic macrocystic mass detected with ultrasonography. Her past medical history was silent. The patient reported upper abdominal discomfort for two months; nausea, vomiting or weight loss were not reported. Physical examination revealed a palpable mass in the epigastrium; scleral icterus was absent. Cross-sectional imaging showed a complex mass of the neck and body of the pancreas, characterized by multiple large cystic spaces separated by thick septa and an area of solid tissue located in the caudal portion of the lesion. The patient underwent total pancreatectomy with splenectomy. Pathological examination revealed a mucinous cystic neoplasm with a component of an undifferentiated carcinoma with osteoclast-like giant cells. Because of the absence of ovarian-type stroma, the lesion was classified as an indeterminate mucin-producing cystic neoplasm of the pancreas. The immunohistochemical studies evidenced no reactivity of osteclast-like giant cells to epithelial markers but showed a positive reactivity to histiocytic markers. Numerous pleomorphic giant cells with an immunohistochemical sarcomatoid profile were present in the undifferentiated carcinoma with osteoclast-like giant cells. A rapid tumor progression was observed: liver metastases were detected after 4 months. The patient received adjuvant chemotherapy (Gemcitabine) but expired 10 months after surgery.

Conclusion: Our case confirms that the presence of a solid area in a cystic pancreatic tumor at cross-sectional imaging should raise a suspicion of malignant transformation. The lack of ovarian-type stroma in a pancreatic mucinous cystic neoplasm and the presence of pleomorphic giant cells in an undifferentiated carcinoma with osteoclast-like giant cells could be a marker of a poor prognosis.

Keywords: Mucinous cystic neoplasm, Intraductal papillary mucinous neoplasm, Osteoclast-like giant cells carcinoma, Pleomorphic giant cell carcinoma, Pancreas

\footnotetext{
* Correspondence: ugocioffi5@gmail.com

${ }^{4}$ Department of Surgery, University of Milan, Milan, Italy

Full list of author information is available at the end of the article
}

(c) 2015 Chiarelli et al. Open Access This article is distributed under the terms of the Creative Commons Attribution 4.0 International License (http://creativecommons.org/licenses/by/4.0/), which permits unrestricted use, distribution, and reproduction in any medium, provided you give appropriate credit to the original author(s) and the source, provide a link to the Creative Commons license, and indicate if changes were made. The Creative Commons Public Domain Dedication waiver (http://creativecommons.org/publicdomain/zero/1.0/) applies to the data made available in this article, unless otherwise stated. 


\section{Background}

The World Health Organization (WHO) classifies pancreatic mucin-producing cystic tumors into two different pathological entities: mucinous cystic neoplasm (MCN) and intraductal papillary mucinous neoplasm (IPMN) [1]. MCNs are thick-walled macrocystic tumors characterized by the absence of communication with ductal system. The distinctive histological feature of an $\mathrm{MCN}$ is a columnar mucin-producing epithelium supported by an ovarian-type stroma; this neoplasm occurs typically in premenopausal women [1-3]. IPMNs are intraductal tumors characterized by epithelial papillary proliferation and mucin hypersecretion causing a typical cystic dilatation of the pancreatic ductal system. IPMNs occur frequently in the head of the gland and are characterized by the communication between the tumor and the pancreatic ducts $[1,3]$. IPMN has an equal gender distribution and occurs frequently in the seventh decade of life [1]. On the basis of epithelial atypia and invasiveness, cystic neoplasms are classified as adenoma, non-invasive carcinoma and invasive carcinoma [1, 3].

The undifferentiated carcinoma is a rare and aggressive form of pancreatic neoplasm. The WHO classification describes two distinct histological types: osteoclast-like giant cell carcinoma (OGCC) and pleomorphic giant cell carcinoma (PGCC) [1]. PGCC shows a sarcomatoid growth pattern, characterized by the presence of pleomorphic mononucleated and multinucleated bizarre giant cells $[1,4]$. OGCC is composed of spindle-shaped or ovoidal mononuclear cells and scattered giant cells with multiple small regular nuclei $[1,4]$.

In 1981, Posen described for the first time the association of a giant cell tumor of the osteoclastic type with a mucous secreting cystic pancreatic neoplasm and since then only 12 cases have been reported $[5,6]$. In a recent review Wada et al. analyzing all the cases in the literature, reported a favourable prognosis for this particular tumor association [6]. We present the second case in the literature of a patient with an indeterminate mucinproducting cystic neoplasm containing a single area of undifferentiated carcinoma with osteoclast- like giant cells, characterized by a rapid disease progression.

\section{Case presentation}

\section{Clincal history and treatment}

A 68 year old caucasian female with a pancreatic cystic neoplasm diagnosed on ultrasonography (US) presented at our Institute in December 2013. Her past medical history was silent. No abuse of ethanol or smoking was reported. The patient reported upper abdominal discomfort for 2 months; nausea, vomiting or weight loss were not referred. The physical examination revealed a palpable mass in the epigastrium; scleral icterus was absent. No other clinical abnormalities were detected.
The US showed a $5 \times 6 \mathrm{~cm}$ pancreatic macrocystic lesion localized in the body of the gland. Laboratory tests showed that blood cell counts and C-reactive protein were normal. Levels of serum glucose, creatinine, albumin, aminotransferase, gamma-glutamyl transferase, alkaline phosphatase and lipase were all within normal limits. The serum levels of the following tumor markers were elevated: carcino-embryonic antigen (CEA) was $196 \mathrm{ng} / \mathrm{ml}$ (normal range $<5 \mathrm{ng} / \mathrm{ml}$ ) and carbohydrate antigen 19-9 (CA 19-9) was $66 \mathrm{U} / \mathrm{ml}$ (normal range $<33 \mathrm{U} / \mathrm{ml}$ ).

The patient underwent a triphasic multidetector computed tomography (CT) scan and a T1, T2-weighted and DWI contrast enhanced magnetic resonance imaging (MRI) with intravenous Gadolinium administration.

The CT scan showed a large complex cystic and solid mass measuring $5 \times 3 \times 6 \mathrm{~cm}$ involving the neck and the body of the pancreas (Fig. 1a). The tumor had a predominant central component characterized by multiple large cystic spaces (up to $3 \mathrm{~cm}$ in diameter) separated by thick septa. A $2 \mathrm{~cm}$ area of low attenuation solid tissue was located between cyst walls in the caudal portion of the lesion. The main pancreatic duct was enlarged in its entirity (diameter $12 \mathrm{~mm}$ ) with a more marked dilatation in the body and tail region. Irregular calcifications were evident in the peripheral portion of the tumor. There was compression of superior mesenteric vein by the mass with a minimal infiltration of the splenic vein. The CT scan of the chest and abdomen did not show any lymphadenopathy, hepatic and pulmonary metastasis.

MRI confirmed the complex pancreatic lesion featured by a large cystic portion with inner irregular septa and a peripheral solid area measuring $2 \mathrm{~cm}$ in the lower portion of the tumor (Fig. 1b). Cholangiopancreatographic images did not demonstrate a communication between the enlarged main pancreatic duct and the cystic mass; ectatic branch ducts were present in the body and tail region.

At laparotomy a large cystic mass involving the body and the neck of pancreas was confirmed. Further exploration showed an infiltration of the head of the gland but ruled out neoplastic spreading to adjacent organs and lymph nodes; the splenic vein was infiltrated by the mass at superior mesenteric veinous junction. Patient underwent total pancreatectomy with splenectomy and lymph node dissection. A US performed on 7th post-operative day ruled out any intra-abdominal fluid collection. Patient developed post-pancreaectomy diabetes which was difficult to control by insulin therapy. The patient was discharged 14 days after the operation.

\section{Histopathological findings}

Macroscopically the pancreas was involved by a $6 \mathrm{~cm}$ wellcircumscribed round mass localized in the neck and the body with infiltration of the head; stomach, duodenum, common bile duct and spleen were not infiltrated. 


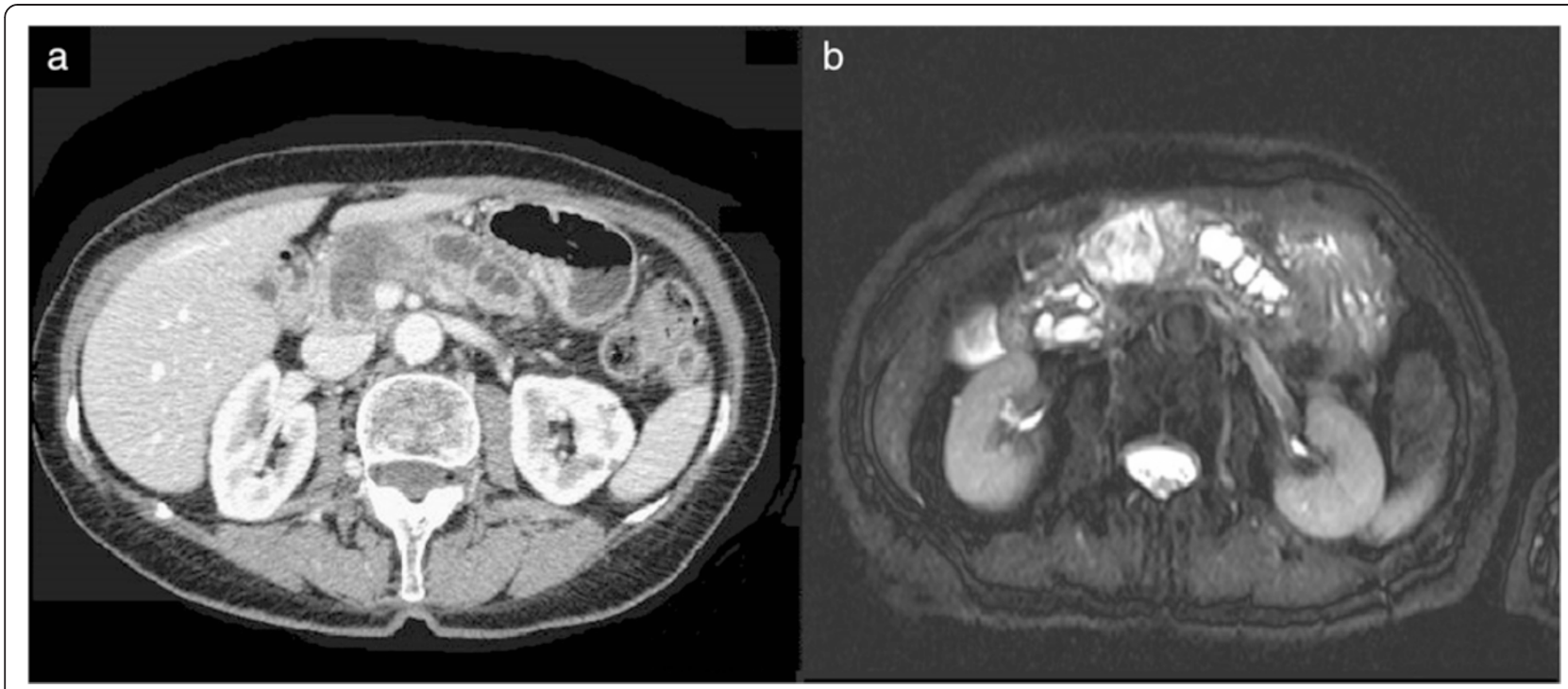

Fig. 1 a Contrast enhanced CT scan demonstrates a complex pancreatic macrocystic mass involving the neck and the body of the pancreas with a peripheral solid portion. $\mathbf{b}$ Axial T2-weighted MRI shows the high-intensity central cystic portion of the mass with inner irregular septa and the peripheral less intense solid tissue determining main duct dilatation

Externally the tumor presented a smooth reddish surface and the pancreatic parenchyma not involved by the lesion appeared fibrotic. On cut-section the lesion showed multilocular macrocystic spaces separated by fibrous septa and filled by a clear viscous mucoid fluid. The main pancreatic duct was ectatic but it was not possible to recognize a communication with the cystic lesion. A $2 \mathrm{~cm}$ single yellow solid area was located in the caudal portion of the mass.

Microscopically the tumor was principally composed of a cystic mucinous part characterized by a columnar mucinous epithelium with atypical nuclei, copious mitoses and stromal invasion. It was not possible to find an ovarian-like stroma (Fig. 2a). In the caudal part of the neoplasm there was a solid area containing mononuclear spindle cells, associated with pleomorphic giant cells (PGCs) and scattered multinucleated osteoclast-like giant cells (OGCs) (Fig. 2b).

The surgical margins were negative for neoplastic infiltration. No lymph node metastases were shown. There was no evidence of perineural or vascular infiltration.

The mononuclear spindle cells and pleomorphic giant cells were immunoreactive for epithelial markers including CK8/18 and CK19, and for vimentin and expressed a weak immunoreactivity for CD68 and a focal immunoreactivity for actin and CD10. The proliferative index (Ki-67) of the mononuclear spindle cells and pleomorphic giant cells was high (approximately $30 \%$ ) (Fig. 3a). Multinucleated

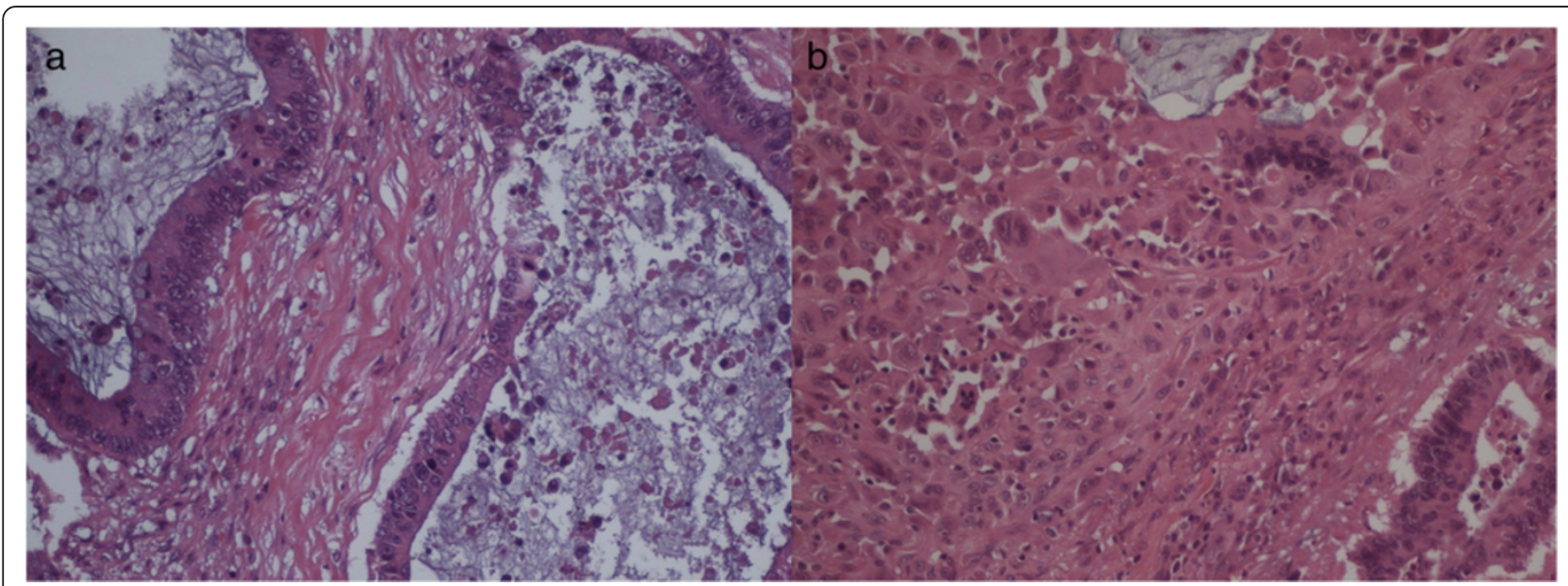

Fig. 2 a Microscopically the tumor is characterized by a predominant cystic lesion composed of a columnar mucinous epithelium with atypical nuclei, numerous mitoses and stromal invasion. An ovarian-type stroma is absent (hematoxylin/eosin staining, 20x). b The solid area contains mononuclear spindle-shaped cells, pleomorphic giant cells and scattered multinucleated osteoclast-like giant cells (hematoxylin/eosin staining, 20x) 


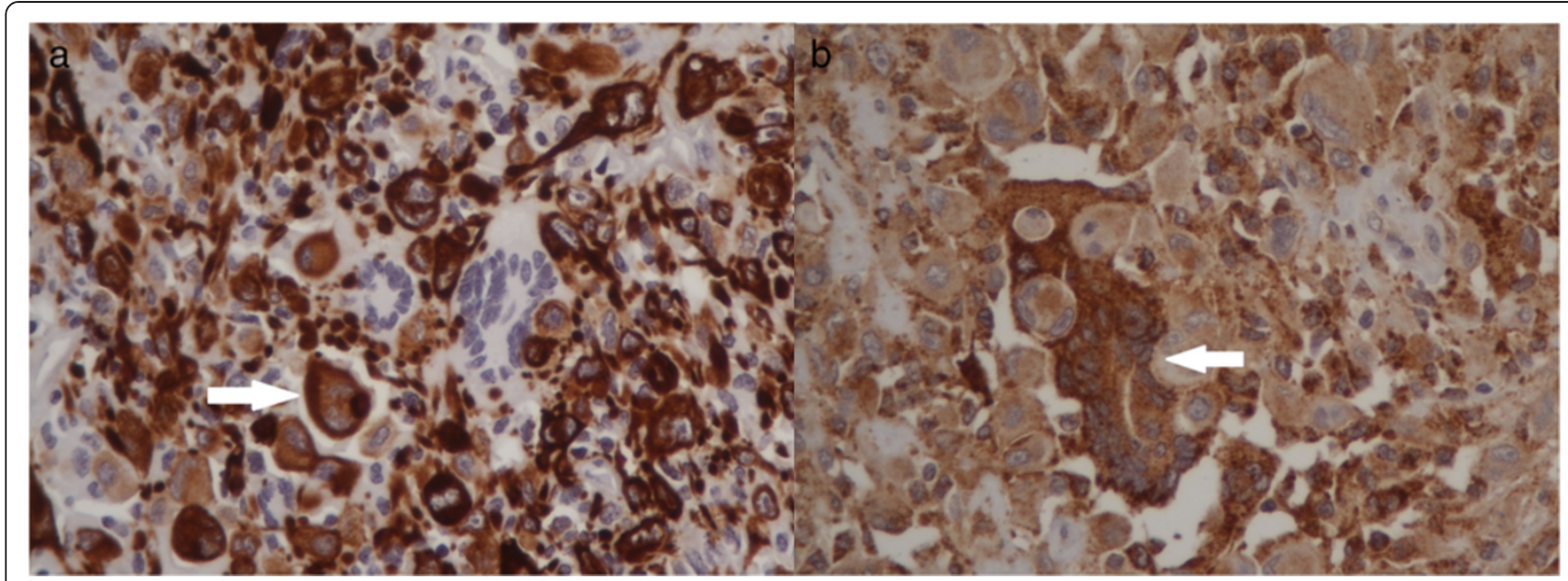

Fig. 3 a Mononuclear spindle-shaped cells and pleomorphic giant cells (arrow) are immunoreactive for epithelial markers (CK8/18), while multinucleated osteoclast-like giant cells are negative (40x). b Mononuclear spindle-shaped cells and pleomorphic giant cells stain weakly for histiocytic marker CD68; in contrast, multinucleated osteoclast-like giant cells show an intense immunoreactivity for CD68 (arrow) (40x)

osteoclast-like giant cells intensely expressed histiocytic marker (CD68) and vimentin but they were negative for epithelial markers (CK8/18 and CK19) and actin. In these cells Ki-67 immunoreaction was negative (Fig. 3b).

The histopathological findings supported the diagnosis of indeterminate mucin-producing cystic neoplasm with a component of osteoclast-like giant cell carcinoma.

\section{Follow-up}

Two months after surgery serum CEA and CA 19-9 decreased to $83 \mathrm{ng} / \mathrm{ml}$ and $31 \mathrm{U} / \mathrm{ml}$, respectively. Nevertheless after 4 months serum CEA increased to $144 \mathrm{ng} / \mathrm{ml}$ and hepatic metastases were founded at follow-up CT scan. Gemcitabine single agent chemotherapy was started $\left(1,00 \mathrm{mg} / \mathrm{m}^{2}\right.$ weekly $\times 7$, then weekly $\times 3$ every 4 weeks $)$. CT scan performed 8 months after surgery showed the progression of liver metastases and appearance of lung metastases. The patient expired 10 months after surgery.

\section{Discussion}

International Consensus Guidelines have established how to diagnose and manage pancreatic cystic tumors [7]. Although their clinical, radiological and pathological features have been defined, in some cases the differential diagnosis between mucinous forms is difficult [8].

In our case the assessment of a correct preoperative diagnosis was difficult due to the clinical and radiological findings. Patient's age and main duct dilatation were elements in favor of IPMN, while female gender and the involvement of the body of the gland leaned towards MCN. However the diagnosis of IPMN was excluded as there was no communication between the cystic mass and the main pancreatic duct.
Tumor size, peripheral calcifications, irregular septa, and the presence of an intramural nodule pointed towards malignant transformation and led to surgical resection. Indeed all these radiological findings are very frequently associated with malignant histology [9].

On the basis of microscopic criteria (nuclear atypia, number of mitoses, and invasion into the stroma), the lesion should be categorized as a mucinous cystoadenocarcinoma. Nevertheless the absence of ovarian-type stroma made us to classify it as an indeterminate mucinproducing cystic neoplasm of the pancreas [7]. In the literature the lack of ovarian-type stroma is more frequent in postmenopausal women and MCNs that do no express ovarian-type stroma have a worse prognosis compared to those which have ovarian-type stroma $[2,10]$.

OGCC is rare pancreatic neoplasm: a US population study based on Surveillance, Epidemiology and End Result (SERR) database evidenced that its incidence is $11 \%$ of all undifferentiated carcinomas of the pancreas [11].

In the past decades the histogenesis of OGCC was debated, but the more recent immunohistochemical studies demonstrate that OGCs present no reactivity to epithelial markers and show a positive reactivity to histiocytic marker $\mathrm{CD} 68$; by contrast, spindle-shaped mononuclear cells express epithelial markers [12, 13]. The immunoreactivity for Ki-67 reveals a low proliferative activity of OGCs and a high proliferative activity for mononuclear cells [13]. These data, as our findings, confirm the hypothesis that spindle-shaped mononuclear cells are neoplastic elements, while OGCs are not neoplastic and may have a histiocytic lineage $[12,13]$.

In our case numerous PGCs were detected in the solid area of the neoplasm. These cells are frequently characterized by immunoreactivity for epithelial markers like 
cytokeratins and CEA and by a high proliferative index; in some cases, PGCs express mesenchymal markers like vimentin [14]. These data support the hypothesis that PGCs are undifferentiated neoplastic cells derived from epithelial elements with a sarcomatoid profile. These histological changes are typical of the epithelial-mesenchimal transition which is a marker of tumor de-differentiation and invasiveness [15].

The simultaneous presence of PGCs and OGCs within the same tumor indicates a possible overlap between the two histological types: some authors propose to classify the mixed giant cell carcinoma as a different histopathological entity containing both osteoclastic and pleomorphic giant cells in significant proportion $[4,14,16]$.

Incongruous data is there in the literature about OGCC prognosis. Early reports based on single case suggested that it might have a better outcome than ordinary ductal carcinoma [17]. However in a series of nine cases all patients but one died within 1 year from diagnosis [12]. In a retrospective analysis of 15 patients with anaplastic carcinoma of the pancreas, all long-term survivors presented a neoplasm containing OGCs and the median survival was significantly better in this histological type [18]. In two small series, OGCCs with a high proportion of PGCs were associated with a shorter survival $[13,19]$ and in an overall analysis of the few reported cases, the presence of a cell population expressing epithelial markers seemed to predict a worse prognosis [20].

Ours is the second case described in the english literature of an indeterminate mucin-producting cystic neoplasm containing an area of undifferentiated carcinoma with osteoclast-like giant cells. In a review that analyzed all cases of MCN associated with OGCC, 10 of 12 patients were alive at follow-up [6]. By contrast our report was remarkable for the rapid progression of the tumor. It is interesting to note that both cystic and solid components of the neoplasm presented histological features of malignancy. Only further studies based on large series with longer follow-up will clarify if the absence of ovarian-type stroma and the presence of PGCs could be related with the outcome of these tumors.

\section{Conclusions}

There are only few case reports in literature of an MCN with a component of OGCC. Due to limited data it is difficult to establish accurately radiological presentation and clinical outcome of these patients. Our case confirms that the presence of solid area in a cystic tumor at cross-sectional imaging should raise a suspicion of malignant transformation. In conclusion, the peculiar histological features of the two neoplasms and the rapid course of the disease make our case remarkable.

\section{Consent}

Written informed consent was obtained from the patient for publication of this Case report and any accompanying images. A copy of the written consent is available for review by the Editor of this journal.

\section{Abbreviations}

WHO: World Health Organization; SEER: Surveillance, Epidemiology and End Result; MCN: Mucinous cystic neoplasm; IPMN: Intraductal papillary mucinous neoplasm; OGCC: Osteoclast-like giant cell carcinoma; PGCC: Pleomorphic giant cell carcinoma; OGCs: Osteoclast-like giant cells; PGCs: Pleomorphic giant cells; CEA: Carcino-embryonic antigen; CA 19-9: Carbohydrate antigen 19-9; US: Ultrasonography; CT: Computed tomography; MRI: Magnetic resonance imaging; CK8/18: Cytokeratin 8/18; CK19: Cytokeratin 19; CD68: Cluster of differentiation 68; CD10: Cluster of differentiation 10.

\section{Competing interest}

None of the contributing authors have any conflict of interest, including specific financial interests or relationships and affiliations relevant to the subject matter or materials discussed in the manuscript.

\section{Authors' contributions}

MC: carried out the study, drafted the manuscript and revised it. AG: collected information of patient and revised the contents of discussion and conclusions of the manuscript. MG: collected information of patient and wrote the contents of clinical history, treatment and follow-up of the manuscript. AM: checked the histopathology and wrote the contents of histopatological findings of the manuscript. FG: revised the contents of the discussion and conclusions of the manuscript. MDS: revised the manuscript. UC: carried out the concept and the design of the study and revised the manuscript. All authors read and approve the final manuscript.

\section{Acknowledgements}

We thank Dr. Gerardo Cioffi, native speaker, for reviewing the English language.

\section{Author details}

'Department of Surgery, Ospedale Alessandro Manzoni, Lecco, Via dell'Eremo 9/11, 23900 Lecco, LC, Italy. ${ }^{2}$ Department of Surgery, University of Milan-Bicocca, Istituti Clinici Zucchi, Via Zucchi, 24, 20900 Monza, MB, Italy. ${ }^{3}$ Department of Pathology, Ospedale Alessandro Manzoni, Lecco, Via dell'Eremo 9/11, 23900, Lecco LC, Italy. ${ }^{4}$ Department of Surgery, University of Milan, Milan, Italy.

Received: 13 June 2015 Accepted: 10 November 2015 Published online: 18 November 2015

\section{References}

1. Bosman FT, Carniero F, Hruban RH, Theise ND, editors. WHO classification of tumours of the digestive system. 4th ed. Lyon: IARC; 2010.

2. Thompson LDR, Becker RC, Przygodzki RM, Adair CF, Heffess CS. Mucinous cystic neoplasm (mucinous cystoadenocarcinoma of low-grade malignant potential) of the pancreas. A clinicopathologic study of 130 cases. Am J Surg Pathol. 1999;23:1-16.

3. Campbell F, Azadeh B. Cystic neoplasm of the exocrine pancreas. Histopathology. 2008;52:539-51.

4. Moore JC, Bentz JS, Hilden K, Adler DG. Osteoclastic and pleomorphic giant cell tumors of the pancreas: a review of clinical, endoscopic, and pathologic features. World J Gastrointest Endosc. 2010;2:15-9.

5. Posen JA. Giant cell tumor of the pancreas of the osteoclastic type associated with a mucous secreting cystadenocarcinoma. Hum Pathol. 1981;12:944-7.

6. Wada T, Itano O, Oshima G, Chiba N, Ishikawa H, Koyama Y, et al. A male case of an undifferentiated carcinoma with osteoclast-like giant cells originating in an indeterminate mucin-producing cystic neoplasm of the pancreas. A case report and review of the literature. World J Surg Oncol. 2011;9:100.

7. Tanaka M, Chari S, Adsay V, Fernandez-del Castillo C, Falconi M, Shimizu M, et al. International consensus guidelines for management of intraductal papillary mucinous neoplasm and mucinous cystic neoplasm of the pancreas. Pancreatology. 2006;6:17-32. 
8. Sarr MG, Murr M, Smyrk TC, Yeo CJ, del-Castillo Fernandez C, Hawes RH, et al. Primary cystic neoplasm of the pancreas: neoplastic disorders of emerging importance - current state-of-the-art and unanswered questions. J Gastrointest Surg. 2003;7:417-28.

9. Sarr MG, Carpenter HA, Prabhakar LP, Orchard TF, Hughes $S$, van Heerden JA, et al. Clinical and pathologic correlation of 84 mucinous cystic neoplasm of the pancreas. Ann Surg. 2000;231:205-12.

10. Zamboni G, Scarpa A, Bogina G, lacono C, Bassi C, Talamini G, et al. Mucinous cystic tumors of the pancreas: clinicopathological features, prognosis, and relationship to other mucinous cystic tumors. Am J Surg Pathol. 1999;23:410-22.

11. Clark CJ, Graham RP, Arun JS, Harmsen WS, Reid-Lombardo KM. Clinical outcomes for anaplastic pancreatic cancer: a population-based study. J Am Coll Surg. 2012;215:627-34.

12. Molberg KH, Heffess C, Delgado R, Albores-Saavedra J. Undifferentiated carcinoma with osteoclast-like giant cells of the pancreas and periampullary region. Cancer. 1998;82:1279-87.

13. Deckard-Janatpour K, Kragel S, Teplitz RL, Min BH, Gumerlock PH, Frey CF, et al. Tumors of the pancreas with osteoclast-like and pleomorphic giant cells. An immunohistochemical and ploidy study. Arch Pathol Lab Med. 1998;122: 266-72.

14. Watanabe M, Miura H, Inoue H, Uzuki M, Noda Y, Fujita N, et al. Mixed osteoclastic/pleomorphic - type giant cell tumor of the pancreas with ductal adenocarcinoma: histochemical and immunohistochemical study with review of the literature. Pancreas. 1997;15:201-8.

15. Lewandrowski KB, Weston L, Dickersin GR, Rattner DW, Compton CC. Giant cell tumor of the pancreas of mixed osteoclastic and pleomorphic cell type: evidence for a histogenetic relationship and mesenchymal differentiation. Hum Pathol. 1990;21:1184-7.

16. Ezenekwe AM, Collins BT, Ponder TB. Mixed osteoclastic/pleomorphic giant cell tumor of the pancreas. Acta Cytol. 2005;49:549-53.

17. Jeffrey I, Crow J, Ellis BW. Osteoclast-type giant cell tumor of the pancreas. J Clin Pathol. 1983:36:1165-70.

18. Strobel O, Hartwig W, Bergmann F, Hinz U, Hackert T, Grenacher L, et al. Anaplastic pancreatic cancer: presentation, surgical management, and outcome. Surgery. 2011;149:200-8.

19. Moore JC, Hilden K, Bentz JS, Pearson RK, Adler DG. Osteoclastic and pleomorphic giant cell tumors of the pancreas diagnosed via EUS-guided FNA: unique clinical, endoscopic, and pathologic findings in a series of 5 patients. Gastrointest Endosc. 2009;69:162-6.

20. Machado MA, Herman P, Montagnini AL, Jukemura J, Leite KR, Machado MC. Benign variant of osteoclast-type giant cell tumor of the pancreas. Importance of the lack of epithelial differentiation. Pancreas. 2001;22:105-7.

\section{Submit your next manuscript to BioMed Central and take full advantage of:}

- Convenient online submission

- Thorough peer review

- No space constraints or color figure charges

- Immediate publication on acceptance

- Inclusion in PubMed, CAS, Scopus and Google Scholar

- Research which is freely available for redistribution 